\title{
Poorer clinicopathologic features and better long-term survival in young than old patients with gallbladder cancer treated with surgical resection
}

\author{
Guo-Qing Jiang ${ }^{1, *}$, Bao-Huan Zhou ${ }^{1,3, *}$, Dou-Sheng Bai ${ }^{1, *}$, Ping Chen ${ }^{1}$, Jian-Jun \\ Qian', Sheng-Jie Jin ${ }^{1}$ and Hao-Jun Yang ${ }^{2}$ \\ ${ }^{1}$ Department of Hepatobiliary and Pancreatic Surgery, Clinical Medical College of Yangzhou University, Yangzhou, China \\ ${ }^{2}$ Department of General Surgery, Changzhou No.2 People's Hospital, Affiliated Hospital of Nanjing Medical University, \\ Changzhou, China \\ ${ }^{3}$ Department of Hepatobiliary and Pancreatic Surgery, Dalian Medical University, Dalian, Liaoning, China \\ *These authors contributed equally to this work \\ Correspondence to: Hao-Jun Yang, email: HaoJunYangDoc@hotmail.com \\ Keywords: gallbladder cancer; age at diagnosis; SEER; survival analysis; surgery \\ Received: August 07, $2017 \quad$ Accepted: December 28, $2017 \quad$ Published: January 02, 2018 \\ Copyright: Jiang et al. This is an open-access article distributed under the terms of the Creative Commons Attribution License 3.0 \\ (CC BY 3.0), which permits unrestricted use, distribution, and reproduction in any medium, provided the original author and source \\ are credited.
}

\section{ABSTRACT}

This article compares the clinical characteristics and prognosis of patients in different age groups with gallbladder cancer (GBC) treated by surgical resection. We retrospectively studied Surveillance, Epidemiology, and End Results (SEER) populationbased data and identified 10,568 patients with GBC who underwent surgical treatment from 1980 to 2013. The patients were categorized according to age at diagnosis: $<60$ years (young group) or $\mathbf{2 6 0}$ years (old group). Five-year cancer-specific survival data were obtained. Kaplan-Meier methods and multivariable Cox regression models were used to analyze long-term survival outcomes and risk factors. Patients in the young group had a higher proportion of white race within-group comparisons, a higher rate of tumors at TNM stage III/IV, a higher frequency of $>5-\mathrm{cm}$ tumors, a lower prevalence of a localized SEER stage, a higher number of lymph nodes dissected ( $\geq 2$ nodes), and a lower proportion of tumors among patients with a widowed marital status, all of which were statistically significant within-group differences $(P<0.001)$. Age at diagnosis was an independent prognostic factor in the multivariate analysis $(P<0.001)$. The 5-year gallbladder cancer cause-specific survival rate was $26.7 \%$ in the young group and $16.2 \%$ in the old group, which showed statistical significance in both the univariate and multivariate analysis $(P<0.001)$. Conclusions Young patients with GBC treated with surgical resection appear to have unique characteristics and a higher cancer-specific survival rate than older patients, although they showed a higher rate of poor biological behavior and advanced-stage disease.

\section{INTRODUCTION}

Gallbladder cancer (GBC) is the most common biliary tract neoplasm worldwide and the fifth most common cancer of the digestive system $[1,2]$. It is considered the most aggressive type of cancer among biliary tract cancers because of its poor prognosis and absence of effective therapy [3]. Although many advances have been made in the diagnosis and treatment of this disease, including surgery, chemotherapy, radiotherapy, and molecular-targeted therapy, the prognosis of GBC is still poor, with a 5-year survival rate of $<5 \%$ [3-6]. This dismal prognosis is due to its aggressive features and the lack of effective screening tests for early detection [7]. Only a small percentage of patients undergo curative surgical resection, and the rate of locoregional recurrence is high.

GBC is infrequent in developed countries but common in some specific geographical regions of 
developing countries [8]. Although Eastern and Central Europe, South and Central America, South Asia, and Japan are endemic areas of gallbladder malignancy, little is known about the pathogenesis and clinical characteristics of GBC in young patients $[9,10]$.

GBC is generally known as a disease of elderly people and rarely develops in younger patients, with an incidence of $0.1 \%$ to $1.0 \%$ in people aged $<30$ years $[11,12]$. Studies have shown that age at diagnosis has a significant impact on survival of patients with various cancers, including liver cancer, colorectal cancer, gastric cancer, and breast cancer; additionally, young patients have a better prognosis and lower mortality associated with major causes of death than do elderly patients [13-16].

Little is known about the effect of age on survival among patients with GBC. Therefore, we investigated the relationship between age and GBC survival in the present study. We used data from the Surveillance, Epidemiology, and End Results (SEER) registry to analyze the effect of age on the clinicopathological features and survival of patients with GBC after surgery.

\section{RESULTS}

\section{Baseline patient characteristics}

We identified 10,568 eligible patients during the 33-year study period (1980-2013), including 2,860 male and 7,708 female patients. The patients were categorized according to age at diagnosis into the young group $(<60$ years of age) and the old group ( $\geq 60$ years of age). The young group comprised 2,860 (27.1\%) patients, and the old group comprised 7,708 $(72.9 \%)$ patients. The median ages in young and old groups were 53 and 75 years, respectively. Within-group comparisons in the young group showed significant differences in race (more frequent in black patients, $P<0.001$ ), years of diagnosis (more prevalent in recent years [2002-2013], $P<0.001$ ), TNM stage (higher frequency of TNM III/IV GBC, $P<0.001$ ), tumor size (higher frequency of $>5-\mathrm{cm}$ tumors, $P<0.001$ ), SEER stage (fewer localized tumors, $P<0.001$ ), number of lymph nodes (LNs) dissected (more patients with $\geq 2$ LNs dissected, $P<0.001$ ), and marital status (lower frequency in widowed patients, $P<0.001$ ). No significant differences in sex $(P=0.404)$, histotypes $(P=0.132)$, or pathological grades $(P=0.257)$ were found between the two groups. Table 1 shows the baseline patient demographics and tumor characteristics.

\section{Impact of age on GBC survival outcomes}

The overall 5-year GBC cause-specific survival (GCSS) was $26.7 \%$ in the young group and $16.2 \%$ in the old group, which showed a significant difference in the univariate log-rank test $(P<0.001)$ (Figure 1). All differences were significant according to the univariate log-rank test (all $P<0.001)$ (Figure 2A). Older age $(P<0.001)$, black race $(P<0.001)$, early year of diagnosis (1980-1990) $(P<0.001)$, adenosquamous carcinoma $(P<$ $0.001)$, poor or anaplastic pathological grade $(P<0.001)$, TNM stage III/IV disease $(P<0.001)$, tumor size of $>5 \mathrm{~cm}(P<0.001)$, SEER distant stage $(P<0.001),<2$ LNs dissected $(P<0.001)$, and a widowed status $(P<$ $0.001)$ were identified as significant risk predictors for poor survival in the univariate analysis (Table 2). When a multivariate analysis with Cox regression was performed, all of the aforementioned variables except race $(P=0.067)$ and year of diagnosis $(P=0.160)$ were independent prognostic factors for poor survival (Table 2). The risk factors were age ( $\geq 60$ years; hazard ratio [HR], 1.453; 95\% confidence interval [CI], 1.363-1.551), histotype (squamous cell carcinoma: HR, 1.615; 95\% CI, 1.2912.021; adenosquamous carcinoma: HR, 1.320; 95\% CI, 1.157-1.506; other: HR, 1.218; 95\% CI, 1.084-1.368), pathological grade (poor or anaplastic tumor: HR, 1.469; 95\% CI, 1.394-1.549; unknown pathological grade: HR, 0.976; 95\% CI, 0.895-1.063), TNM stage (stage III/IV: HR, 1.173; 95\% CI, 0.999-1.378; unknown stage: HR, $1.304 ; 95 \%$ CI, 1.131-1.503), tumor size (3- to $5-\mathrm{cm}$ tumor: HR, 1.186; 95\% CI, 1.063-1.323; >5-cm tumor: HR, 1.253; 95\% CI, 1.100-1.428; unstated tumor size: HR, 1.376; 95\% CI, 1.263-1.499), SEER stage (regional stage: HR, 2.135; 95\% CI, 2.006-2.273; distant stage: HR, 3.645; 95\% CI, 3.410-3.896; unstaged: HR, 1.780; 95\% CI, 1.366-2.320), $\geq 2$ LNs dissected (HR, 0.510; 95\% CI, 0.474-0.548), and marital status (married: HR, 0.805; 95\% CI, 0.761-0.852; never married: HR, 0.943; 95\% CI, 0.866-1.027; divorced/separated: HR, 0.927; 95\% CI, 0.843-1.019).

\section{Stratified analysis of age on GBC survival based on different pathological grades}

We further analyzed the effects of age on 5-year GCSS in patients with tumors of different pathological grades. The results showed that young patients had a significantly better 5-year GCSS than older patients in the univariate analysis of different pathological grades $(P<0.001)$ (Table 3). We found no significant differences in the subgroup of pathological grades among the different age groups (Table 1), but the pathological grade was an independent factor for 5-year GCSS in both the univariate and multivariate analyses $(P<0.001)$ (Table 2$)$. Conversely, we discovered that older patients had a lower survival rate for all pathological grades: For tumors with well/moderate pathological grades, older patients had a $16.3 \%$ reduction in 5-year GCSS compared with young patients $(P<0.001)$. For tumors with poor/anaplastic pathological grades, older patients had a $4.4 \%$ reduction in 5 -year GCSS compared with young patients $(P<0.001)$. Age was also validated as an independent survival factor in the multivariate Cox regression for tumors with well/ 
Table 1: Baseline demographic and tumor characteristics of patients with gallbladder cancer in the SEER database

\begin{tabular}{|c|c|c|c|c|}
\hline \multirow[t]{2}{*}{ Characteristic } & Total & $<60$ & $\geq 60$ & $P$ \\
\hline & $\begin{array}{l}10568 \\
N(\%)\end{array}$ & $\begin{array}{c}(n=2165) \\
N(\%)\end{array}$ & $\begin{array}{c}(n=8403) \\
N(\%)\end{array}$ & \\
\hline Sex & & & & 0.404 \\
\hline Male & $2860(27.1)$ & $590(27.3)$ & $2270(27.0)$ & \\
\hline Female & 7708 (72.9) & $1575(72.7)$ & $6133(73.0)$ & \\
\hline Race & & & & $<0.001$ \\
\hline White & $8450(80.2)$ & $1601(74.3)$ & $6849(81.7)$ & \\
\hline Black & $948(9.0)$ & $306(14.2)$ & $642(7.7)$ & \\
\hline Other* & $1144(10.9)$ & $248(11.5)$ & $896(10.7)$ & \\
\hline Year of diagnosis ${ }^{\dagger}$ & & & & $<0.001$ \\
\hline 1980-1990 & $1837(17.4)$ & $287(13.3)$ & $1550(18.4)$ & \\
\hline 1991-2001 & $3004(28.4)$ & $587(27.1)$ & $2417(28.8)$ & \\
\hline $2002-2013$ & $5727(54.2)$ & $1291(59.6)$ & $4436(52.8)$ & \\
\hline Histotype & & & & 0.132 \\
\hline Adenocarcinoma & $9639(91.2)$ & $1952(90.2)$ & $7687(91.5)$ & \\
\hline $\begin{array}{l}\text { Squamous cell } \\
\text { carcinoma }\end{array}$ & $117(1.1)$ & $30(1.4)$ & $87(1.0)$ & \\
\hline $\begin{array}{l}\text { Adenosquamous } \\
\text { carcinoma }\end{array}$ & $348(3.3)$ & $72(3.3)$ & $276(3.3)$ & \\
\hline Other $^{\#}$ & $464(4.4)$ & $111(5.1)$ & $353(4.2)$ & \\
\hline Pathological grading & & & & 0.257 \\
\hline Well/moderate & $5321(50.4)$ & $1089(50.3)$ & $4232(50.4)$ & \\
\hline Poor/anaplastic & $3941(37.3)$ & $829(38.3)$ & $3112(37.0)$ & \\
\hline Unknown & $1306(12.4)$ & $247(11.4)$ & $1059(12.6)$ & \\
\hline TNM stage & & & & $<0.001$ \\
\hline $\mathrm{I} / \mathrm{II}$ & $796(7.5)$ & $153(7.1)$ & $643(7.7)$ & \\
\hline III/IV & $1089(10.3)$ & $276(12.7)$ & $813(9.7)$ & \\
\hline Unknown & $8683(82.2)$ & $1736(80.2)$ & $6947(82.7)$ & \\
\hline Tumor size & & & & $<0.001$ \\
\hline$<3 \mathrm{~cm}$ & $1387(13.1)$ & 295 (13.6) & $1092(13.0)$ & \\
\hline $3-5 \mathrm{~cm}$ & $898(8.5)$ & $209(9.7)$ & $689(8.2)$ & \\
\hline$>5 \mathrm{~cm}$ & $530(5.0)$ & $142(6.6)$ & $388(4.6)$ & \\
\hline Not stated & $7753(73.4)$ & $1519(70.2)$ & $6234(74.2)$ & \\
\hline SEER stage & & & & $<0.001$ \\
\hline Localized & $4676(44.2)$ & $829(38.3)$ & $3847(45.8)$ & \\
\hline Regional & $3015(28.5)$ & $657(30.3)$ & $2358(28.1)$ & \\
\hline Distant & $2742(25.9)$ & $663(30.6)$ & 2079 (24.7) & \\
\hline Unstaged & $135(1.3)$ & $16(0.7)$ & $119(1.4)$ & \\
\hline No. of LNs dissected & & & & $<0.001$ \\
\hline$<2$ & $7402(83.1)$ & $1391(74.2)$ & $6011(85.5)$ & \\
\hline$\geq 2$ & $1506(16.9)$ & $484(25.8)$ & $1022(14.5)$ & \\
\hline Marital status & & & & $<0.001$ \\
\hline Widowed & $3001(29.5)$ & $109(5.3)$ & $2892(35.7)$ & \\
\hline
\end{tabular}




$\begin{array}{lccc}\text { Married } & 5106(50.7) & 1290(62.3) & 3870(47.8) \\ \text { Never married } & 1152(11.3) & 417(20.1) & 735(9.1) \\ \text { Divorced/separated } & 855(8.4) & 255(12.3) & 600(7.4)\end{array}$

Abbreviations: SEER: Surveillance, Epidemiology, and End Results; LN: lymph node.

*Other includes American Indian/Alaska native, Asian/Pacific Islander, and unknown.

The early and middle years of diagnosis were 11 years in duration; the latest was 12 years.

\#Other cancers included signet ring carcinoma, small cell carcinoma, giant and spindle cell carcinoma, non-small cell carcinoma, carcinoma not otherwise specified, and undifferentiated carcinoma.

moderate pathological grades (old: HR, 1.695; 95\% CI, $1.559-1.843 ; P<0.001)$ and for tumors with poor/ anaplastic pathological grades (old: HR, $1.307 ; 95 \% \mathrm{CI}$, $1.202-1.420 ; P<0.001$ ) (Table 3; Figure 2A, 2B).

\section{Stratified analysis of age on GBC survival based on different TNM stages}

We also analyzed the effects of age on 5-year GCSS in tumors of different TNM stages. We found that age was an independent risk factor for poor survival in patients with tumors of each TNM stage, both in the univariate and multivariate analysis $(P<0.001)$. We also discovered that older patients again had a lower survival rate at all TNM stages: For stage I/II tumors, older patients had a $32.0 \%$ reduction in 5-year GCSS compared with young patients ( $75.9 \%$ vs. $43.9 \%$, respectively; $P<0.001$ ). For stage III/ IV tumors, older patients had a $9.8 \%$ reduction in 5-year GCSS compared with young patients $(20.0 \%$ vs. $10.2 \%$, respectively; $P<0.001$ ) (Table 4; Figure 2C, 2D).

\section{Stratified analysis of age on GBC survival based on different tumor sizes}

We also analyzed the effects of age on 5-year GCSS for tumors of different sizes. We found that age was an

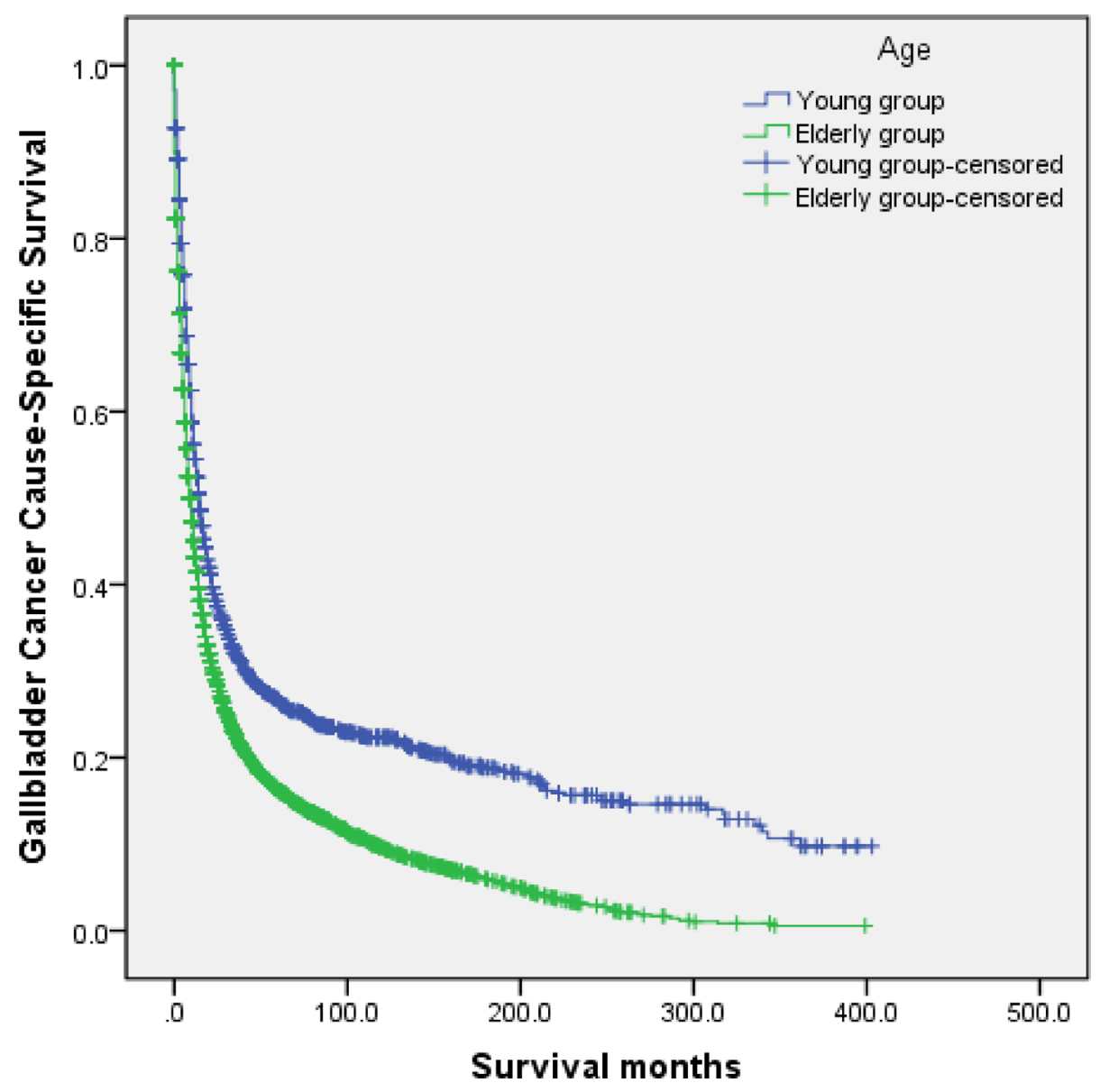

Figure 1: Survival curves of patients with gallbladder cancer treated with surgical resection between the young and older groups. $\chi^{2}=205.371, P<0.001$. 
Table 2: Univariate and multivariate survival analysis of the influence of age at diagnosis on gallbladder cancer cause-specific survival in the SEER database

\begin{tabular}{|c|c|c|c|c|c|c|}
\hline \multirow[b]{2}{*}{ Variable } & \multirow[b]{2}{*}{ Total } & \multirow[b]{2}{*}{ 5-year CCS } & \multicolumn{2}{|c|}{ Univariate analysis } & \multicolumn{2}{|c|}{ Multivariate analysis } \\
\hline & & & $\begin{array}{c}\text { Log rank } \chi^{2} \\
\text { test }\end{array}$ & $P$ & HR (95\% CI) & $\boldsymbol{P}$ \\
\hline Sex & & & 0.826 & 0.363 & & NI \\
\hline Male & $2860(27.1)$ & $17.6 \%$ & & & & \\
\hline Female & 7708 (72.9) & $18.6 \%$ & & & & \\
\hline Age & & & 205.371 & $<0.001$ & & $<0.001$ \\
\hline$<60$ & $2165(20.5)$ & $26.7 \%$ & & & Reference & \\
\hline$\geq 60$ & $8403(79.5)$ & $16.2 \%$ & & & $1.453(1.363-1.551)$ & \\
\hline Race & & & 21.828 & $<0.001$ & & 0.067 \\
\hline White & $8450(80.2)$ & $17.8 \%$ & & & Reference & \\
\hline Black & $948(9.0)$ & $16.3 \%$ & & & $1.049(0.965-1.139)$ & 0.262 \\
\hline Other* & 1144 (10.9) & $23.0 \%$ & & & $0.927(0.857-1.002)$ & 0.056 \\
\hline Year of diagnosis $\dagger$ & & & 138.565 & $<0.001$ & & 0.160 \\
\hline 1980-1990 & $1837(17.4)$ & $14.5 \%$ & & & Reference & \\
\hline 1991-2001 & $3004(28.4)$ & $16.1 \%$ & & & $0.914(0.826-1.012)$ & 0.082 \\
\hline $2002-2013$ & $5727(54.2)$ & $20.9 \%$ & & & $0.905(0.815-1.004)$ & 0.059 \\
\hline Histotype & & & 122.370 & $<0.001$ & & $<0.001$ \\
\hline Adenocarcinoma & $9639(91.2)$ & $19.0 \%$ & & & Reference & \\
\hline $\begin{array}{l}\text { Squamous cell } \\
\text { carcinoma }\end{array}$ & $117(1.1)$ & $12.1 \%$ & & & $1.615(1.291-2.021)$ & $<0.001$ \\
\hline $\begin{array}{l}\text { Adenosquamous } \\
\text { carcinoma }\end{array}$ & $348(3.3)$ & $8.6 \%$ & & & $1.320(1.157-1.506)$ & $<0.001$ \\
\hline Other ${ }^{\#}$ & $464(4.4)$ & $12.4 \%$ & & & $1.218(1.084-1.368)$ & 0.001 \\
\hline Pathological grading & & & 725.160 & $<0.001$ & & $<0.001$ \\
\hline Well/moderate & $5321(50.4)$ & $24.4 \%$ & & & Reference & \\
\hline Poor/anaplastic & $3941(37.3)$ & $9.5 \%$ & & & $1.469(1.394-1.549)$ & $<0.001$ \\
\hline Unknown & $1306(12.4)$ & $20.5 \%$ & & & $0.976(0.895-1.063)$ & 0.573 \\
\hline TNM stage & & & 277.632 & $<0.001$ & & $<0.001$ \\
\hline $\mathrm{I} / \mathrm{II}$ & $796(7.5)$ & $49.8 \%$ & & & Reference & \\
\hline III/IV & $1089(10.3)$ & $12.8 \%{ }^{\dagger \dagger}$ & & & $1.173(0.999-1.378)$ & 0.052 \\
\hline Unknown & $8683(82.2)$ & $17.3 \%$ & & & $1.304(1.131-1.503)$ & $<0.001$ \\
\hline Tumor size & & & 264.355 & $<0.001$ & & $<0.001$ \\
\hline$<3 \mathrm{~cm}$ & $1387(13.1)$ & $32.9 \%$ & & & Reference & \\
\hline $3-5 \mathrm{~cm}$ & $898(8.5)$ & $21.6 \%$ & & & $1.186(1.063-1.323)$ & 0.002 \\
\hline$>5 \mathrm{~cm}$ & $530(5.0)$ & $16.2 \%$ & & & $1.253(1.100-1.428)$ & 0.001 \\
\hline Not stated & $7753(73.4)$ & $15.9 \%$ & & & $1.376(1.263-1.499)$ & $<0.001$ \\
\hline SEER stage & & & 2319.379 & $<0.001$ & & $<0.001$ \\
\hline Localized & $4676(44.2)$ & $33.1 \%$ & & & Reference & \\
\hline Regional & $3015(28.5)$ & $8.9 \%$ & & & $2.135(2.006-2.273)$ & $<0.001$ \\
\hline Distant & $2742(25.9)$ & $3.4 \%$ & & & $3.645(3.410-3.896)$ & $<0.001$ \\
\hline Unstaged & $135(1.3)$ & $12.4 \%$ & & & $1.780(1.366-2.320)$ & $<0.001$ \\
\hline No. of LNs dissected & & & 134.124 & $<0.001$ & & $<0.001$ \\
\hline$<2$ & $7402(83.1)$ & $16.4 \%$ & & & Reference & \\
\hline$\geq 2$ & $1506(16.9)$ & $31.5 \%$ & & & $0.510(0.474-0.548)$ & $<0.001$ \\
\hline Marital status & & & 129.256 & $<0.001$ & & $<0.001$ \\
\hline Widowed & $3001(29.5)$ & $13.5 \%$ & & & Reference & \\
\hline
\end{tabular}




$\begin{array}{lcccc}\text { Married } & 5106(50.7) & 20.9 \% & 0.805(0.761-0.852) & <0.001 \\ \text { Never married } & 1152(11.3) & 19.5 \% & 0.943(0.866-1.027) & 0.181 \\ \text { Divorced/ } & 855(8.4) & 17.8 \% & 0.927(0.843-1.019) & 0.115 \\ \text { separated } & & & & \end{array}$

Abbreviations: SEER: Surveillance, Epidemiology, and End Results; CCS: cause-specific survival; HR: hazard ratio; CI: confidence interval; LN: lymph node; NI: not included in the multivariate survival analysis.

*Other includes American Indian/Alaska native, Asian/Pacific Islander, and unknown.

The early and middle years of diagnosis were 11 years in duration; the latest was 12 years.

\#Other cancers included signet ring carcinoma, small cell carcinoma, giant and spindle cell carcinoma, non-small cell carcinoma, carcinoma not otherwise specified, and undifferentiated carcinoma.

"3-year CCS. Because the TNM stage records according to the AJCC Cancer Staging Manual (7th edition) in the SEER database began in 2009 and ended in 2013, the 5-year CCS did not exist.

independent risk factor for poor survival in patients with different tumor sizes in both the univariate and multivariate analysis $(P<0.050)$. We also discovered that older patients again had a lower survival rate for all tumor sizes: For $<3$-cm tumors, older patients had a $22.1 \%$ reduction in 5 -year GCSS compared with young patients ( $50.4 \%$ vs. $28.3 \%$, respectively; $P<0.001)$. For 3 - to 5 -cm tumors, older patients had a $6.0 \%$ reduction in 5 -year GCSS compared with young patients $(26.3 \%$ vs. $20.3 \%$, respectively; $P=0.022$ ). For $>5$-cm tumors, older patients had a $12.7 \%$ reduction in 5-year GCSS compared with young patients $(25.5 \%$ vs. $12.8 \%$, respectively; $P<0.001$ ) (Table 5, Figure 2E-2G).

\section{Stratified analysis of age on GBC survival based on different SEER stages}

We likewise analyzed the effects of age on 5-year GCSS for different tumor sizes. We found that age was an independent risk factor for poor survival in patients with each SEER stage in both the the univariate and multivariate analysis $(P<0.050)$. We also discovered that older patients again had a lower survival rate at all SEER stages: For localized stage tumors, older patients had a $24.1 \%$ reduction in 5-year GCSS compared with young patients $(53.1 \%$ vs. $29.0 \%$, respectively; $P<0.001)$. For regional stage tumors, older patients had an $8.0 \%$ reduction in 5-year GCSS compared with young patients (15.2\% vs. $7.2 \%$, respectively; $P<0.001)$. For distant stage tumors, older patients had a $1.7 \%$ reduction in 5 -year GCSS compared with young patients $(4.7 \%$ vs. $3.0 \%$, respectively; $P<0.001$ ) (Table 6 , Figure $2 \mathrm{H}-2 \mathrm{~J}$ ).

\section{Identification of cutoff points for number of LNs dissected in terms of 5-year GCSS}

To assess the influence of different numbers of LNs dissected on GCSS and guarantee sufficient statistical power, we analyzed individual results using different numbers of LNs dissected ranging from 0 to 16 . The 5 -year GCSS was calculated for patients with $\geq \mathrm{N}$ nodes (number of LNs dissected) and $<\mathrm{N}$ nodes. The number of
LNs dissected was a prognosis factor only for $\mathrm{N}$ ranging from 0 to 15 . The maximum $\chi^{2}$ log-rank value of 265.629 $(P<0.001)$ was produced, applying 2 as the optimal cutoff value to divide the cohort into high- and low-risk subsets in terms of 5-year GCSS (Table 7). Furthermore, the mean number of LNs dissected was 1.18. Hence, in the present study, patients were divided into those with $<2$ and $\geq 2$ LNs dissected.

\section{DISCUSSION}

Some studies have suggested young patients have longer overall survival times and lower mortality rates than older patients among many important causes of cancer death [13-16]. In this study, we used the SEER database to determine the relationship between age at diagnosis and survival. The present study also showed that young patients had significantly better GCSS than did older patients. Moreover, in the multivariable analyses, the risk for older patients lasted even after adjusting for histologic type, pathological grade, TNM stage, tumor size, SEER stage, number of LNs dissected, and marital status. We first found that older patients were at high risk of cancer-specific mortality and that the age at diagnosis can be a protective prognostic factor in patients with GBC.

GBC is known to occur three times more frequently in female than male patients $[6,17]$, which was confirmed in our study; female and male patients accounted for $72.9 \%$ and $27.1 \%$ of all patients with GBC, respectively (Table 1). Among women, higher gravidity and parity increase the risk of developing this cancer [18]. However, the sex ratio in the present study was different from that in previous reports showing no significant difference between the incidence in men and women; female patients accounted for $72.9 \%$ and $72.7 \%$ of the entire group and young group of patients with GBC, respectively (Table 1). In contrast, female patients accounted for $72 \%$ and $75 \%$ of the entire group and young group of patients with GBC, respectively, in a study by Dutta et al. [19] performed in India. The incidence of GBC increases with age [17]. The average age at diagnosis is 72 years, and more than twothirds of people with GBC are aged $>60$ years [20]. 
Kazmi et al. reported that, compared with older patients, young patients aged less than 45 years with GBC showed higher expression of cholecystokinin type A receptor that was overexpressed for stage III as compared with stage II GBC and for poorly and moderately differentiated tumors compared with well-differentiated ones, and they also found that young patients were associated with less differentiated tumors compared with older patients, which is consistent with the results of the present study. However, they showed the mean survival
A

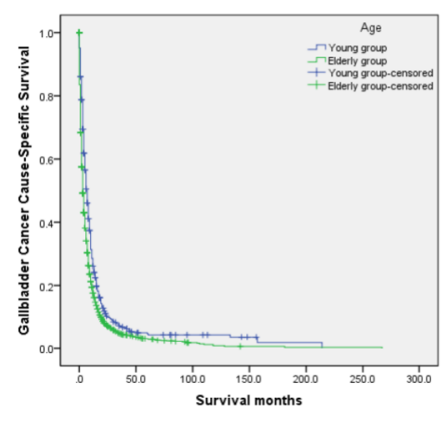

D

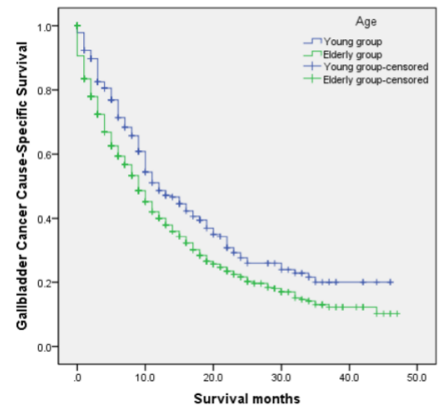

G

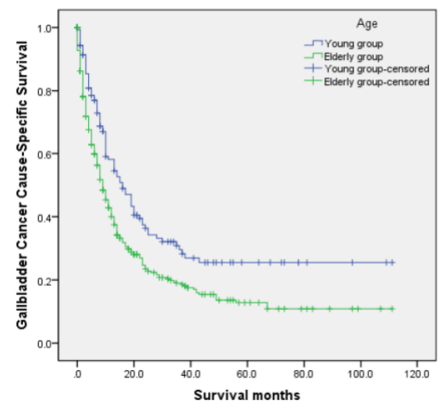

J

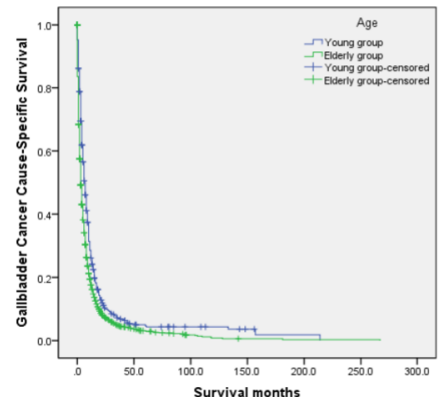

B

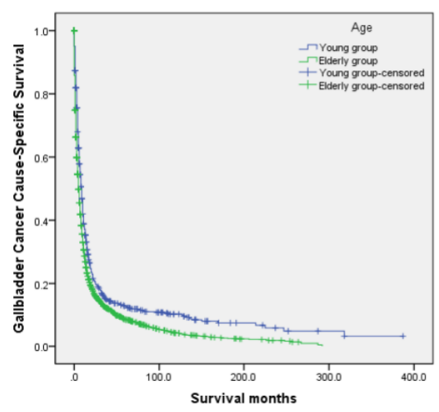

E

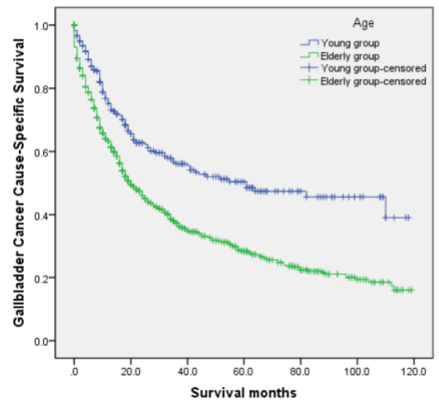

H

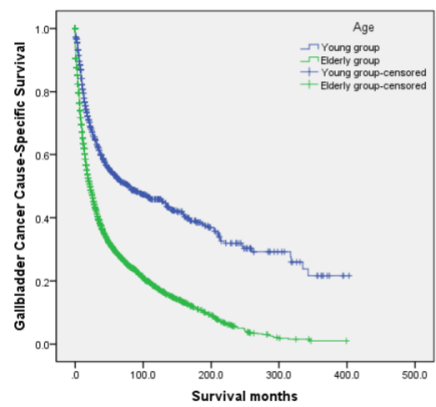

C

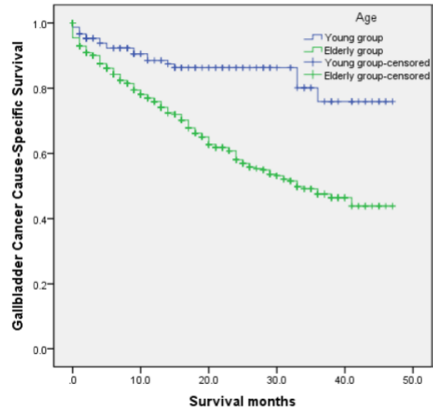

$\mathbf{F}$

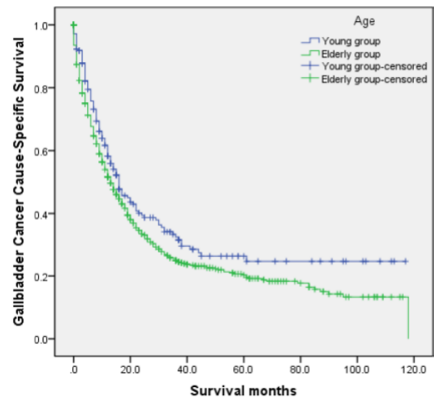

I

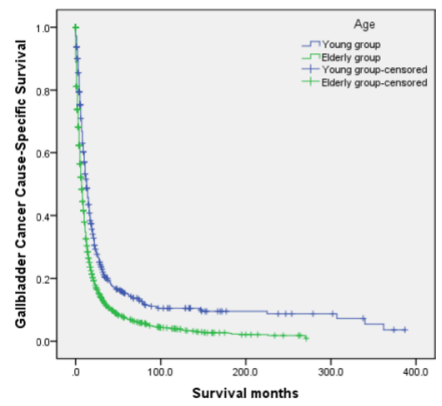

Figure 2: Survival curves of patients with gallbladder cancer treated with surgical resection according to age at diagnosis. (A) Well/moderate: $\chi^{2}=161.07, P<0.001$. (B) Poor/anaplastic: $\chi^{2}=43.489, P<0.001$. (C) TNM I/II: $\chi^{2}=23.063, P<0.001$. (D) TNM III/IV: $\chi^{2}=13.317, P<0.001$. (E) Tumor size of $<3 \mathrm{~cm}: \chi^{2}=36.853, P<0.001$. (F) Tumor size of $3-5 \mathrm{~cm}: \chi^{2}=5.274, P=0.022$. (G) Tumor size of $>5 \mathrm{~cm}: \chi^{2}=13.730, P<0.001$. (H) Localized: $\chi^{2}=223.600, P<0.001$. (I) Regional: $\chi^{2}=83.634, P<0.001$. (J) Distant: $\chi^{2}=53.322, P<0.001$. SEER: Surveillance, Epidemiology, and End Results. 
Table 3: Univariate and multivariate analysis of age at diagnosis on gallbladder cancer cause-specific survival based on different pathological grades

\begin{tabular}{|c|c|c|c|c|c|c|}
\hline \multirow{2}{*}{ Variable } & \multirow{2}{*}{ Total } & \multirow{2}{*}{ 5-year CCS } & \multicolumn{2}{|c|}{ Univariate analysis } & \multicolumn{2}{|c|}{ Multivariate analysis } \\
\hline & & & Log rank $\chi^{2}$ test & $P$ & HR $(95 \%$ CI) & $P$ \\
\hline \multicolumn{7}{|l|}{$\begin{array}{l}\text { Pathological } \\
\text { grading }\end{array}$} \\
\hline Well/moderate & 5321 & & 161.070 & $<0.001$ & & $<0.001$ \\
\hline \multicolumn{7}{|l|}{ Age } \\
\hline$<60$ & & $37.5 \%$ & Reference & & Reference & \\
\hline$\geq 60$ & & $21.2 \%$ & 161.070 & $<0.001$ & $1.695(1.559-1.843)$ & \\
\hline Poor/anaplastic & 3941 & & 43.489 & $<0.001$ & & $<0.001$ \\
\hline \multicolumn{7}{|l|}{ Age } \\
\hline$<60$ & & $12.9 \%$ & Reference & & Reference & \\
\hline$\geq 60$ & & $8.5 \%$ & 161.070 & $<0.001$ & $1.307(1.202-1.420)$ & \\
\hline
\end{tabular}

Abbreviations: CCS: cause-specific survival; HR: hazard ratio; CI: confidence interval.

Table 4: Univariate and multivariate analysis of age at diagnosis on gallbladder cancer cause-specific survival based on different TNM stages

\begin{tabular}{|c|c|c|c|c|c|c|}
\hline \multirow{2}{*}{ Variable } & \multirow{2}{*}{ Total } & \multirow{2}{*}{ 5-year CCS } & \multicolumn{2}{|c|}{ Univariate analysis } & \multicolumn{2}{|c|}{ Multivariate analysis } \\
\hline & & & Log rank $\chi^{2}$ test & $P$ & HR (95\% CI) & $P$ \\
\hline \multicolumn{7}{|c|}{ TNM stage } \\
\hline I/II & 796 & & 23.063 & $<0.001$ & & $<0.001$ \\
\hline \multicolumn{7}{|l|}{ Age } \\
\hline$<60$ & & $75.9 \%$ & Reference & & Reference & \\
\hline$\geq 60$ & & $43.9 \%$ & 23.063 & $<0.001$ & $2.886(1.826-4.562)$ & \\
\hline III/IV & 1089 & & 13.317 & $<0.001$ & & $<0.001$ \\
\hline \multicolumn{7}{|l|}{ Age } \\
\hline$<60$ & & $20.0 \%$ & Reference & & Reference & \\
\hline$\geq 60$ & & $10.0 \%$ & 13.317 & $<0.001$ & $1.367(1.149-1.628)$ & \\
\hline
\end{tabular}

Abbreviations: CCS: cause-specific survival; HR: hazard ratio; CI: confidence interval.

was significantly shorter in young patients as compared to older patients, which different from the outcome of the present study may be due to the relatively small sample size $(n=39)$ [21]. Do et al. demonstrated that the diseaserelated survival rate after 13.5 months was significantly more favorable for young patients less than 45 years, which is similar to the present results [22]. However, pathological grades did not differ significantly in the two groups, which may be due to the relatively small sample size only with 10 young patients in their study.

It is well known that tumors with an advanced TNM stage and poor differentiation tend to have a more dismal prognosis than well-differentiated and moderately differentiated tumors. In the present study, despite the significantly higher incidence of poor prognostic factors such as poor differentiation, advanced TNM stage, large tumor size $(>5 \mathrm{~cm})$, and distant SEER stage in the young than old group (Table 1), young patients with GBC had a better 5-year GCSS in each subgroup of pathological grade (Table 3), TNM stage (Table 4), tumor size (Table 5), and SEER stage (Table 6). These findings were demonstrated in both the univariate and multivariate analysis. Our results are consistent with some recently published articles exploring other tumors, including colorectal cancer, gastric cancer, and breast cancer [14-16]. Carcinoma in young patients shows poorer biological behavior, but the better overall condition, better immune state, and faster postoperative recovery in these patients may compensate for this poorer biological behavior [14]. Older patients had poorer survival, which might have occurred because aging lowers the immune response, increases oxidative stress, shortens telomeres, and causes accumulation of senescent cells $[23,24]$. Overall, a good performance status is essential for successful postoperative treatments and extensive lymphadenectomy. Young patients are more inclined to gain the benefits of all therapeutic options 
Table 5: Univariate and multivariate analysis of age at diagnosis on gallbladder cancer cause-specific survival based on different tumor sizes

\begin{tabular}{|c|c|c|c|c|c|c|}
\hline \multirow{2}{*}{ Variable } & \multirow{2}{*}{ Total } & \multirow{2}{*}{ 5-year CCS } & \multicolumn{2}{|c|}{ Univariate analysis } & \multicolumn{2}{|c|}{ Multivariate analysis } \\
\hline & & & Log $\operatorname{rank} \chi^{2}$ test & $\boldsymbol{P}$ & HR (95\% CI) & $P$ \\
\hline \multicolumn{7}{|c|}{ Tumor size } \\
\hline$<3 \mathrm{~cm}$ & 1387 & & 36.853 & $<0.001$ & & $<0.001$ \\
\hline \multicolumn{7}{|l|}{ Age } \\
\hline$<60$ & & $50.4 \%$ & Reference & & Reference & \\
\hline$\geq 60$ & & $28.3 \%$ & 36.853 & $<0.001$ & $1.797(1.479-2.184)$ & \\
\hline $3-5 \mathrm{~cm}$ & 898 & & 5.274 & 0.022 & & 0.025 \\
\hline \multicolumn{7}{|l|}{ Age } \\
\hline$<60$ & & $26.3 \%$ & Reference & & Reference & \\
\hline$\geq 60$ & & $20.3 \%$ & 36.853 & $<0.001$ & $1.253(1.029-1.525)$ & \\
\hline$>5 \mathrm{~cm}$ & 530 & & 13.730 & $<0.001$ & & $<0.001$ \\
\hline \multicolumn{7}{|l|}{ Age } \\
\hline$<60$ & & $25.5 \%$ & Reference & & Reference & \\
\hline$\geq 60$ & & $12.8 \%$ & 36.853 & $<0.001$ & $1.557(1.221-1.985)$ & \\
\hline
\end{tabular}

Abbreviations: CCS: cause-specific survival; HR: hazard ratio; CI: confidence interval.

Table 6: Univariate and multivariate analysis of age at diagnosis on gallbladder cancer cause-specific survival based on different SEER stages

\begin{tabular}{|c|c|c|c|c|c|c|}
\hline \multirow{2}{*}{ Variable } & \multirow{2}{*}{ Total } & \multirow{2}{*}{ 5-year CCS } & \multicolumn{2}{|c|}{ Univariate analysis } & \multicolumn{2}{|c|}{ Multivariate analysis } \\
\hline & & & Log rank $\chi^{2}$ test & $P$ & HR $(95 \%$ CI $)$ & $P$ \\
\hline \multicolumn{7}{|c|}{ SEER stage } \\
\hline Localized & 4676 & & 223.600 & $<0.001$ & & $<0.001$ \\
\hline \multicolumn{7}{|l|}{ Age } \\
\hline$<60$ & & $53.1 \%$ & Reference & & Reference & \\
\hline$\geq 60$ & & $29.0 \%$ & 223.600 & $<0.001$ & $2.158(1.944-2.395)$ & \\
\hline Regional & 3015 & & 83.634 & $<0.001$ & & $<0.001$ \\
\hline \multicolumn{7}{|l|}{ Age } \\
\hline$<60$ & & $15.2 \%$ & Reference & & Reference & \\
\hline$\geq 60$ & & $7.2 \%$ & 83.634 & $<0.001$ & $1.534(1.394-1.688)$ & \\
\hline Distant & 2742 & & 53.322 & $<0.001$ & & $<0.001$ \\
\hline \multicolumn{7}{|l|}{ Age } \\
\hline$<60$ & & $4.7 \%$ & Reference & & Reference & \\
\hline$\geq 60$ & & $3.0 \%$ & 53.322 & $<0.001$ & $1.380(1.258-1.513)$ & \\
\hline
\end{tabular}

Abbreviations: SEER: Surveillance, Epidemiology, and End Results; CCS: cause-specific survival; HR: hazard ratio; CI: confidence interval.

because their health condition is generally better and they are more likely to tolerate toxicities associated with chemotherapy, while older patients tend to be undertreated because of their poor clinical condition.

Some studies have shown that marital status is an independent prognostic factor for worse survival in the patients with colorectal cancer and gallbladder cancer $[25,26]$. Marital status was also reported as an independent prognostic factor for worse survival in the patients with GBC [27]. These are consistent with the findings of the present study. Our study also showed that compared with the young group, the older group included more widows and exhibited poorer survival. Psychosocial factors might explain the relationship between marital status and survival. Married patients show less distress, depression, and anxiety and more social support 
Table 7: Univariate analysis of the influence of different total lymph node counts on patients with gallbladder cancer

\begin{tabular}{|c|c|c|c|c|}
\hline $\begin{array}{l}\text { Total lymph } \\
\text { node count }\end{array}$ & No. & $\begin{array}{c}\text { 5-year } \\
\text { CCS }\end{array}$ & $\begin{array}{c}\text { Log-rank } \\
\chi^{2}\end{array}$ & $P$ \\
\hline 0 & 5671 & $15.7 \%$ & 255.418 & $<0.001$ \\
\hline$\geq 1$ & 3237 & $24.5 \%$ & & \\
\hline$<2$ & 7402 & $16.4 \%$ & 265.629 & $<0.001$ \\
\hline$\geq 2$ & 1506 & $31.5 \%$ & & \\
\hline$<3$ & 7847 & $17.0 \%$ & 206.395 & $<0.001$ \\
\hline$\geq 3$ & 1061 & $33.1 \%$ & & \\
\hline$<4$ & 8102 & $17.5 \%$ & 161.062 & $<0.001$ \\
\hline$\geq 4$ & 806 & $33.3 \%$ & & \\
\hline$<5$ & 8259 & $17.8 \%$ & 127.651 & $<0.001$ \\
\hline$\geq 5$ & 649 & $33.1 \%$ & & \\
\hline$<6$ & 8373 & $18.0 \%$ & 94.798 & $<0.001$ \\
\hline$\geq 6$ & 535 & $32.6 \%$ & & \\
\hline$<7$ & 8477 & $18.2 \%$ & 64.621 & $<0.001$ \\
\hline$\geq 7$ & 431 & $30.9 \%$ & & \\
\hline$<8$ & 8552 & $18.2 \%$ & 43.215 & $<0.001$ \\
\hline$\geq 8$ & 356 & $29.5 \%$ & & \\
\hline$<9$ & 8608 & $18.5 \%$ & 33.569 & $<0.001$ \\
\hline$\geq 9$ & 300 & $28.3 \%$ & & \\
\hline$<10$ & 8650 & $18.5 \%$ & 30.799 & $<0.001$ \\
\hline$\geq 10$ & 258 & $29.7 \%$ & & \\
\hline$<11$ & 8695 & $18.6 \%$ & 22.084 & $<0.001$ \\
\hline$\geq 11$ & 213 & $27.7 \%$ & & \\
\hline$<12$ & 8736 & $18.7 \%$ & 14.407 & $<0.001$ \\
\hline$\geq 12$ & 172 & $25.7 \%$ & & \\
\hline$<13$ & 8759 & $18.7 \%$ & 11.388 & 0.01 \\
\hline$\geq 13$ & 149 & $24.8 \%$ & & \\
\hline$<14$ & 8788 & $18.8 \%$ & 8.383 & 0.04 \\
\hline$\geq 14$ & 120 & $22.3 \%$ & & \\
\hline$<15$ & 8801 & $18.8 \%$ & 4.346 & 0.037 \\
\hline$\geq 15$ & 107 & $20.3 \%$ & & \\
\hline$<16$ & 8820 & $18.8 \%$ & 2.583 & 0.108 \\
\hline$\geq 16$ & 88 & $19.5 \%$ & & \\
\hline
\end{tabular}

Abbreviation: CCS: cause-specific survival.

than unmarried patients $[28,29]$. Two meta-analyses acknowledged that depression increased cancer mortality by $19 \%$ and $39 \%$, respectively $[30,31]$. Decreased psychosocial support and increased psychological stress have been shown to decrease immune function, which may promote tumor progression and mortality [29, 32-33]. Further, perceived lack of social support could decrease the activity of natural killer cells [34]. Additionally, many neuroendocrine mediators and cytokines present in patients with depression and stress have been found to be linked with an increased rate of cancer metastasis [33]. Finally, depression and poor quality of life may lead to increased production of vascular endothelial growth factor, which may promote endothelial cell migration, proliferation, and proteolytic activity [35].

Although the present study was a large populationbased study, it has several potential limitations. First, we investigated SEER data to evaluate the relationship between age at diagnosis and the postoperative prognosis of GBC, but the SEER database was lacking some information about 
their treatment programs. Treatment measures, economic status, marital status, surgical techniques, and social status may have changed for some patients during the therapeutic process, and these changes may have affected the outcomes. Second, some data regarding pathological grade, TNM stage, and tumor size may have been inexhaustivefor example, many patients lost these data. Many other factors can contribute to an elevated risk of various health problems and affect the survival of patients with GBC. Third, the study included only patients who had undergone surgical resection for GBC. As such, the patients are not representative of patients with unresectable GBC or who had refused surgical intervention for various reasons. Fourth, the SEER GBC database lacks quality data on adjuvant therapy, comorbidities, surgical techniques, and recurrence. Finally, we could not employ psychological tests to confirm whether psychosocial factors played an important role in the poor survival of unmarried patients.

In summary, the primary endpoints of this study were GCSS and overall survival in different age groups after surgical treatment. Compared with older patients, young patients with GBC (age of $<60$ years) appear to have unique clinicopathological features and a higher GCSS after surgery, although they showed higher proportions of unfavorable biological behavior and advanced-stage disease.

\section{MATERIALS AND METHODS}

\section{Patient selection in the SEER database}

The SEER program of the National Cancer Institute is an authoritative source of information on cancer incidence and survival in the United States. The SEER program registries routinely collect patient clinical data including demographics, primary tumor site, tumor morphology and stage at diagnosis, first course of treatment, follow-up for survival, and so on. SEER currently collects and publishes cancer incidence and survival data from 18 populationbased cancer registries that represent approximately 30\% of the population in the United States.

SEER data contain no identifiers and have been widely used for studies of the relationship between prognostic factors and survival outcomes in patients with cancer. We used SEER*Stat 8.1.5 software to identify patients who were histopathologically diagnosed with GBC from 1980 to 2013. SEER registry patients eligible for this cohort included those with the following histologic type ICD-O-3: adenocarcinoma (8140, 8141, 8143, 8147), papillary adenocarcinoma (8260, 8261, 8262, 8263), mucinous adenocarcinoma $(8480,8481)$, adenocarcinoma with metaplasia $(8571,8572,8573,8574,8575,8576)$, papillary carcinoma $(8050,8051,8052)$, duct carcinoma $(8500,8501,8503,8504,8507,8508)$, squamous cell carcinoma $(8070,8071,8072,8073,8074,8075,8076$, $8078)$, adenosquamous carcinoma $(8560,8562)$, or other cancers including signet ring carcinoma (8490), small cell carcinoma $(8041,8043)$, giant and spindle cell carcinoma (8030-8035), non-small cell carcinoma (8046), carcinoma not otherwise specified $(8010,8011,8012,8013,8014$, $8015)$, or undifferentiated carcinoma $(8020,8021,8022)$. We excluded all other histologic types from the study.

Patients were excluded if they were $<18$ years of age at diagnosis; did not undergo surgical resection for GBC; had multiple primary malignant neoplasms, of which the GBC was not the first; and who had an unknown cause of death or unknown survival length.

According to the SEER staging system, tumors that remained in situ or confined to the organ of origin were considered to be localized, tumors that invaded locally or metastasized to regional LNs were regarded as regional, and those that traveled to distant organs were considered to be distant.

\section{Statistical analysis}

The following demographic and clinicopathological factors were assessed: sex, age, race, primary tumor site, year of diagnosis, histotype, pathological grade, TNM stage, tumor size, SEER stage, number of LNs dissected, survival months, vital status, and marital status at the time of diagnosis. The TNM stage was determined according to the criteria described in the American Joint Committee on Cancer (AJCC) Cancer Staging Manual (7th edition). We categorized patients into either the young group ( $<60$ years of age) or old group ( $\geq 60$ years of age). Patients were excluded if they were $<18$ years of age at the time of diagnosis.

The primary endpoint of the study was GCSS, which was calculated from the date of diagnosis to the date of GBC cause-specific death. Deaths attributed to the cancer of interest were treated as events, and deaths of other causes were treated as censored observations.

The baseline patient demographics and tumor characteristics were compared using the chi-square test. The GBC death rate was compared between groups using the Kaplan-Meier method. Risk factors for the survival outcome were analyzed using multivariable Cox regression models. All statistical analyses were performed using the statistical software package SPSS for Windows, version 22 (IBM Corp., Armonk, NY, USA). Statistical significance was set at a two-sided $P$ value of $<0.05$.

\section{CONFLICTS OF INTEREST}

The authors made no disclosures.

\section{FUNDING}

This work was supported by the Project of Invigorating Health Care through Science, Technology and Education: Jiangsu Provincial Medical Youth Talent (QNRC2016331). 


\section{REFERENCES}

1. Kanthan R, Senger JL, Ahmed S, Kanthan SC. Gallbladder Cancer in the 21st Century. Journal of oncology. 2015, 2015: 967472.

2. Miller G, Jarnagin WR. Gallbladder carcinoma. Eur J Surg Oncol. 2008; 34:306-12.

3. Zhu AX, Hong TS, Hezel AF, Kooby DA. Current management of gallbladder carcinoma. Oncologist. 2010; 15:168-181.

4. Gourgiotis S, Kocher HM, Solaini L, Yarollahi A, Tsiambas E, Salemis NS. Gallbladder cancer. Am J Surg. 2008; 196:252-264.

5. Kakaei F, Beheshtirouy S, Nejatollahi SM, Zarrintan S, Mafi MR. Surgical treatment of gallbladder carcinoma: a critical review. Updates Surg. 2015; 67:339-351.

6. Miller G, Jarnagin WR. Gallbladder carcinoma. Eur J Surg Oncol. 2008; 34:306-312.

7. Dutta U. Gallbladder cancer: can newer insights improve the outcome? J Gastroenterol Hepatol. 2012; 27:642-653.

8. Sharma A, Sharma KL, Gupta A, Yadav A, Kumar A. Gallbladder cancer epidemiology, pathogenesis and molecular genetics: Recent update. World J Gastroenterol. 2017; 23:3978-3998.

9. Lazcano-Ponce EC, Miquel JF, Munoz N, Herrero R, Ferrecio C, Wistuba II, Alonso de Ruiz P, Aristi Urista G, Nervi F. Epidemiology and molecular pathology of gallbladder cancer. CA Cancer J Clin. 2001; 51:349-364.

10. Kapoor VK. Gallbladder cancer: a global perspective. J Surg Oncol. 2006; 93:607-609.

11. Piehler JM, Crichlow RW. Primary carcinoma of the gallbladder. Surg Gynecol Obstet. 1978; 147:929-942.

12. Litwin MS. Primary carcinoma of the gallbladder. A review of 78 patients. Arch Surg. 1967; 95:236-240.

13. Zhang W, Jiang R, Hou J, Sun B. Clinicopathological features and prognostic factors of young patients with surgically treated liver cancer. Medicine (Baltimore). 2015; 94:e684.

14. Li Q, Cai G, Li D, Wang Y, Zhuo C, Cai S. Better long-term survival in young patients with non-metastatic colorectal cancer after surgery, an analysis of 69,835 patients in SEER database. PLoS One. 2014; 9:e93756.

15. Al-Refaie WB, Hu CY, Pisters PW, Chang GJ. Gastric adenocarcinoma in young patients: a population-based appraisal. 2011; 18:2800-2807.

16. Chen HL, Zhou MQ, Tian W, Meng KX, He HF. Effect of Age on Breast Cancer Patient Prognoses: A PopulationBased Study Using the SEER 18 Database. 2016; 11:e0165409.

17. Lai CH, Lau WY. Gallbladder cancer-a comprehensive review. Surgeon. 2008; 6:101-110.

18. Randi G, Franceschi S, La Vecchia C. Gallbladder cancer worldwide: geographical distribution and risk factors. Int J Cancer. 2006; 118:1591-1602.
19. Dutta U, Nagi B, Garg PK, Sinha SK, Singh K, Tandon RK. Patients with gallstones develop gallbladder cancer at an earlier age. European journal of cancer prevention. 2005; $14: 381-385$

20. Kanthan R, Senger JL, Ahmed S, Kanthan SC. Gallbladder Cancer in the 21st Century. J Oncol. 2015; 2015:967472.

21. Kazmi HR, Chandra A, Baghel K, Singh A, Nigam J, Parmar D, Mahdi AA, Goel SK, Kumar S. Differential expression of cholecystokinin A receptor in gallbladder cancer in the young and elderly suggests two subsets of the same disease? Biomed Res Int. 2014; 2014:625695.

22. Do SI, Lee HW, Sohn JH, Kim K. Clinicopathologic characteristics of young patients with gallbladder cancer. Pathol Res Pract. 2017; 213:189-193.

23. Fulop T, Larbi A, Kotb R, de Angelis F, Pawelec G. Aging, immunity, and cancer. Discov Med. 2011; 11:537-550.

24. Hoeijmakers JH. DNA damage, aging, and cancer. N Engl J Med. 2009; 361:1475-1485.

25. Li Q, Gan L, Liang L, Li X, Cai S. The influence of marital status on stage at diagnosis and survival of patients with colorectal cancer. Oncotarget. 2015; 6:7339-7347. https:// doi.org/10.18632/oncotarget.3129.

26. Bai DS, Chen P, Qian JJ, Jin SJ, Jiang GQ. Effect of marital status on the survival of patients with gallbladder cancer treated with surgical resection: a population-based study. Oncotarget. 2017; 8:26404-26413. https://doi.org/10.18632/ oncotarget. 15476

27. Li X, Liu Y, Wang Y, Ruan C, Wang H, Liang X, Sun Y, Hu $Z$. The influence of marital status on survival of gallbladder cancer patients: a population-based study. Sci Rep. 2017; 7:5322.

28. Goldzweig G, Andritsch E, Hubert A, Brenner B, Walach N, Perry S, Baider L. Psychological distress among male patients and male spouses: what do oncologists need to know? Ann Oncol. 2010; 21:877-883.

29. Garssen B, Goodkin K. On the role of immunological factors as mediators between psychosocial factors and cancer progression. Psychiatry research. 1999; 85:51-61.

30. Satin JR, Linden W, Phillips MJ. Depression as a predictor of disease progression and mortality in cancer patients: a meta-analysis. Cancer. 2009; 115:5349-5361.

31. Pinquart M, Duberstein PR. Depression and cancer mortality: a meta-analysis. Psychol Med. 2010; 40:1797-1810.

32. Sklar LS, Anisman H. Stress and coping factors influence tumor growth. Science. 1979; 205:513-515.

33. Moreno-Smith M, Lutgendorf SK, Sood AK. Impact of stress on cancer metastasis. Future oncology. 2010; 6:1863-1881.

34. Levy SM, Herberman RB, Whiteside T, Sanzo K, Lee J, Kirkwood J. Perceived social support and tumor estrogen/ progesterone receptor status as predictors of natural killer cell activity in breast cancer patients. Psychosom medicine. 1990; 52:73-85.

35. Ferrara N, Davis-Smyth T. The biology of vascular endothelial growth factor. Endocr Rev. 1997; 18:4-25. 